\title{
Sustained business competitive advantage with data analytics
}

\author{
Adarsh Garg* \\ Galgotias University, \\ Plot No-2, Sec-17A, Yamuna Expressway, \\ Greater Noida, Gautam Buddh Nagar, India \\ Email: adarsh.15@hotmail.com \\ *Corresponding author \\ D.P. Goyal
}

Management Development Institute,

Mehrauli Road, Sukhrali, Gurugram, India

Email: dpgoyal@mdi.ac.in

\begin{abstract}
In today's highly networked and digital business, data is the only gold element with extensive capability to create business value which we have never seen in the traditionally executed business. This new business world is stimulated by analytics and its ability to make the most of data for sustained competitive advantage. The organisations need to adapt new technologies to prevent the wearing out of the existing knowledge and sustain competitively for a long period according to the increasing customer demands. Analytics has the power to forecast future happenings based on some data which is available to the organisation, so making use of the data with analytics. However, new technology, here data analytics, alone will be of little use if the strategic managers lack to understand the business context in which the forecasted knowledge is useful and help in sustained competitive advantage. A strong framework needs to be in place to integrate analytics with the knowledge base of the organisation along with skilled managers. This research paper is an attempt to provide a theoretical framework and its empirical analysis to apply analytics effectively so as to remove uncertainties in business for its sustainability.
\end{abstract}

Keywords: data analytics; competitive advantage; sustainability; technology.

Reference to this paper should be made as follows: Garg, A. and Goyal, D.P. (2019) 'Sustained business competitive advantage with data analytics', Int. J. Business and Data Analytics, Vol. 1, No. 1, pp.4-15.

Biographical notes: Adarsh Garg is a Doctorate in Information Systems with Post-graduation in Computer Applications. She has extensive experience in academia, research as well as industry. She has published over 30 research papers in refereed international/national journals of repute and authored technical books. Her interest areas include information systems, software engineering, business analytics, big data, e-commerce, environment sustainability, e-governance and green IT.

D.P. Goyal is a Professor of Management Information Systems and Dean (graduate programs, accreditations and rankings) at Management Development Institute (MDI), Gurugram and a Visiting Professor at the Aarhus University, 


\begin{abstract}
Aarhus, Denmark. He is a Post-graduate in Business Management and doctorate in Management Information Systems. He has more than three decades of corporate, teaching, and research experience to his credit. He has published over 60 research papers in refereed international/national journals of repute. His teaching and research interest areas include management information systems; IS strategy; enterprise resource planning systems; knowledge management; IS value for business; business process management and e-governance.
\end{abstract}

\title{
1 Introduction
}

Sustainability has become a norm in recent years, with realisation of various laws and regulations to protect environment. The business world also understands the significance of environment sustainability (Garg and Singla, 2017) and its importance in gaining a competitive advantage. The competitive advantage exists when any business reveals its existence in the market with more success in comparison to its competitors (Peteraf, 1993). The sustainability, here, refers to environmental sustainability within the business context because the increased level of customer demands and expectations is forcing the decision-makers to rapidly raise their infrastructure there by using more natural resources directly (manufacturing) (Song et al., 2017) or indirectly(service industry). Consequently, the growing demand of sustainability in business becomes the primary challenge for the managers (Marques et al., 2010; Park-Poaps and Rees, 2010), which may lead to goodwill and economic implications. This entire situation makes the decision-making process more cumbersome and time consuming for the strategic level managers.

Information technology (IT) plays a major role in enhancing the ability of managers to take decisions and thus in gaining competitive advantage. The use of data analytics tools can help the managers to foresee the changes in the market by responding to the changes quickly and make value out of it (Wamba et al., 2017). Before the data analytics tools can be used it is also essential to develop a data repository of the organisational functions. Further, data analytics, alone will be of little use if the strategic managers lack to understand the business context in which the forecasted knowledge is useful and help in sustained competitive advantage. In a recent report, only $25 \%$ of the organisations reported that the use of analytics has 'significantly' improved their organisation's outcomes (Deloitte, 2013). Hence, the main focus of this article is to develop a framework which shows a high level of link between data/knowledge repository, data analytics tools and understanding of business context by strategic managers so as to harness the maximum benefit from the use of data analytics for sustainability. Here data analytics pertains to using analytics tools for real time data generation which massively includes data generation in distributed environment too with a concept of virtualisation.

Creating a data repository and using data analytics tools can be attained with high level technology, which support in decision making process. However, data-driven decision-making environment is crucial, where the strategic managers make decisions based on data rather than gut feeling. Here, it is imperative to know the important dimensions to be included to enhance data analytics capabilities as appropriate management skills are also essential for all data driven decisions and data analytics be treated as dynamic capability of the organisation for competitive advantage. 
The existing literature also revealed the positive impact of use of data analytics tools on performance of the organisation by foreseeing the transformation in the market and acting with greater speed and efficiency (Roberts and Grover, 2012), make faster decisions (Brown et al., 2011; Brynjolfsson and McAfee, 2012; Wamba et al., 2017) and thus to have an edge over other market players. Data analytics is an important tool in current business environment with intense competition (Baesens et al., 2016). The paper, primarily, deliberate on the impact of data analytics use (dynamic capability) along with managerial skills (Intellectual capital) on sustainability of the organisation be it any sector.

\section{Theoretical background}

\subsection{Business analytics (BA) and competitive advantage}

BA focuses on the application of data analytical techniques to find solutions to various business issues by improving decision making (Davenport, 2006). This activity is dependent on the acquisition of data from various resources, assimilation and sharing of a new knowledge for decision making (Joshi et al., 2010), which is termed as business intelligence. In academic research, business intelligence refers to a range of information technologies, information generating techniques and output tools (Wixom and Watson, 2010). However, a more recent term of business intelligence and analytics has been proposed (Chen et al., 2012) due to difficulty in distinguishing the technical capabilities of business intelligence and BA separately (Salam et al., 2014). Besides, the decision making process has also become more data oriented and reliant on analytical capabilities of business intelligence applications (Sallam et al., 2014), which in turn have data analytics as a major constituent.

A number of theoretical perspectives have been in use to conduct study of the role analytics in organisational competitive advantage and the relationship between them. Some recent studies use the idea of dynamic capabilities to explain the business competitive advantage (Ramakrishnan et al., 2015; Seddon et al., 2017). Here, capabilities are defined as an "organizational capacity to arrange resources, generally in combination, by means of organizational processes, to affect a desired end" (Ambrosini et al., 2009). Whereas BA are theoretically explained as an organisation's ability to set up analytics technology and human resources for competitive advantage and thus the sustainability. Therefore, considering BA as an organisational capability, to a certain extent than just as a technical advantage, is a measure to establish a relationship between BA/data analytics and competitive advantage (Sharma et al., 2010).

Other theories like the dynamic capabilities viewpoint also explicitly acknowledge the importance of capabilities in achieving greater organisational performance (Pavlou and El Sawy, 2010; Wamba et al., 2017). The dynamic capabilities are structured organisational practices that change the ordinary capabilities of the organisations and enabling them to achieve competitive advantage through adaptation to a changing business environment (Helfat et al., 2007; Helfat and Peteraf, 2009). As the organisational environment evolves, the ability to see new opportunities and challenges is an important constituent of dynamic capabilities. Foreseeing is directly related to the business strategy (Teece, 2014). Given the large volume of data that must be gathered and processed in order to detect opportunities and challenges in the internal and external 
business environment (Ambrosini et al., 2009; Hodgkinson and Healey, 2011), foreseeing provides a important knowledge imparting functions which limit the amount and dimensions of data which must be interpreted (Helfat and Peteraf, 2014). The advances of dynamic capabilities viewpoint has motivated sustainable competitive advantage (Ambrosini and Bowman, 2009) and the correlation between dynamic capabilities and competitive advantage has evolved over a period of time (Arend and Bromiley, 2009; Helfat and Peteraf, 2009). The organisations must focus on the continuous application of dynamic capabilities in order to have a competitive advantage over other market players (Zott, 2003). Also, measures of the performance of dynamic capabilities should include how well the dynamic capability enables the organisation to make a change (Helfat et al., 2007). This activity is dependent on the acquisition of data from various resources, assimilation and sharing of a new knowledge for decision making (Joshi et al., 2010). Managers collect data about their competitors from various resources that are internal and external to the organisation. According to Mintzberg, managers spend up to $80 \%$ of their time communicating, acquiring and replacing data. The channels of communication (Mintzberg, 1973) are both formal and informal. Data is necessary to reduce the level of uncertainty in analysis of data.

It is important to ensure the realistic outcome of the data received by managers with elaborate description of various issues to arrive at the best decisions. However, the data received for decision makers may be biased, and consequently, the ensuing decision may be far from the best decision. To have a competitive advantage and improve organisational performance, data about competitors needs to acquired, modified, filtered at different levels and understood. Data is understood for different aspects like

- Level of details

a aggregated

b accurate

c predicted

- Source

a internal

b external

- Time period

a short time

b long time

- Decision

a judgemental

b analytical.

Data sources also include the macro-environment. They include political, economic, social, technological, legal, and environmental factors (Collins, 2010). Data acquisition for all these factors is essential to analyse and use it in decision making process for the organisation to gain competitive advantage.

Current research emphasises the importance of BA in applications of dynamic capabilities for decision making for competitive advantage and thus the sustainability of business. 


\section{Research model and hypotheses}

Rapid global progression of the knowledge wealth and tremendous competition, organisations has exposed the organisations to ever increasing challenges to sustain their competitiveness. To survive in this world dynamic capability has emerged as an important dimension for the growth and it has attracted a massive response from research in the area of strategic management (Teece, 2007; Ambrosini et al., 2009; Li and Liu, 2014). When we focus on strategic management, then besides dynamic capabilities of the organisation, the intellectual capabilities also come to light. In current business scenario, advanced IT is the major driver of the business with emphasis on availability of data analytical tools, data repository. The organisations create value from IT resources, for instance, resources and skills (Grover and Kohli, 2012; Chae et al., 2014).

A competitive advantage of the business is dependent on dynamic capabilities (Teece et al., 1997) and looking at the dependency of the organisation heavily on IT capabilities to foresee the needs and challenges of the market. Data analytics comes under the broad term of dynamic capability. It analyses data in a timely manner so as to gain insights (Roberts and Grover, 2012; Akter et al., 2016). However many organisations have not shown the benefit of investing in data analytics (Chen et al., 2012). Thus the process of transmitting benefit of IT as dynamic capability to the competitive advantage needs to be focused on. This article is an attempt to develop a framework where the managerial skills as moderating dimension other than dynamic capability (IT-data analytics) is included for sustainability (competitive advantage) of the organisation.

1 Data analytics capability provides competitive advantage to an organisation in highly dynamic scenario even when there is abundance of strategic resources (Akter et al., 2016). This enables the understanding of data analytics capability as organisation's dynamic capability which can improve sustainability.

2 On the other hand, a few organisations after investing heavily on data analytics do not show the competitive advantage (Chen et al., 2012). This sheds a light on the need of including intellectual capabilities as the moderating dimensions. Thus managerial skills are equally important to understand the business context to reap maximum benefit out of data analytics for competitive advantage.

Thus a complete data-driven environment is essential for effective decision making and hence the competitive advantage. Table 1 depicts all the important components of data-driven environment.

Table 1 Components of data-driven environment for decision-making process

\begin{tabular}{lc}
\hline Dynamic capability components & Intellectual capability components \\
\hline Advanced IT-infrastructure & Ability to understand business context \\
Data repository & Data analysts \\
Data analytics tools & Decision-making \\
Knowledge base & \\
\hline
\end{tabular}

Source: Own adaptation

The research model as depicted in Figure 1, integrates various dimensions of dynamic capability and intellectual capabilities, discussed above, to explain the use of data 
analytics as well as managerial skills to create a data-driven environment which is essential while taking decisions helping in business sustainability.

Figure 1 A research model depicting the relationship between components of data-driven environment

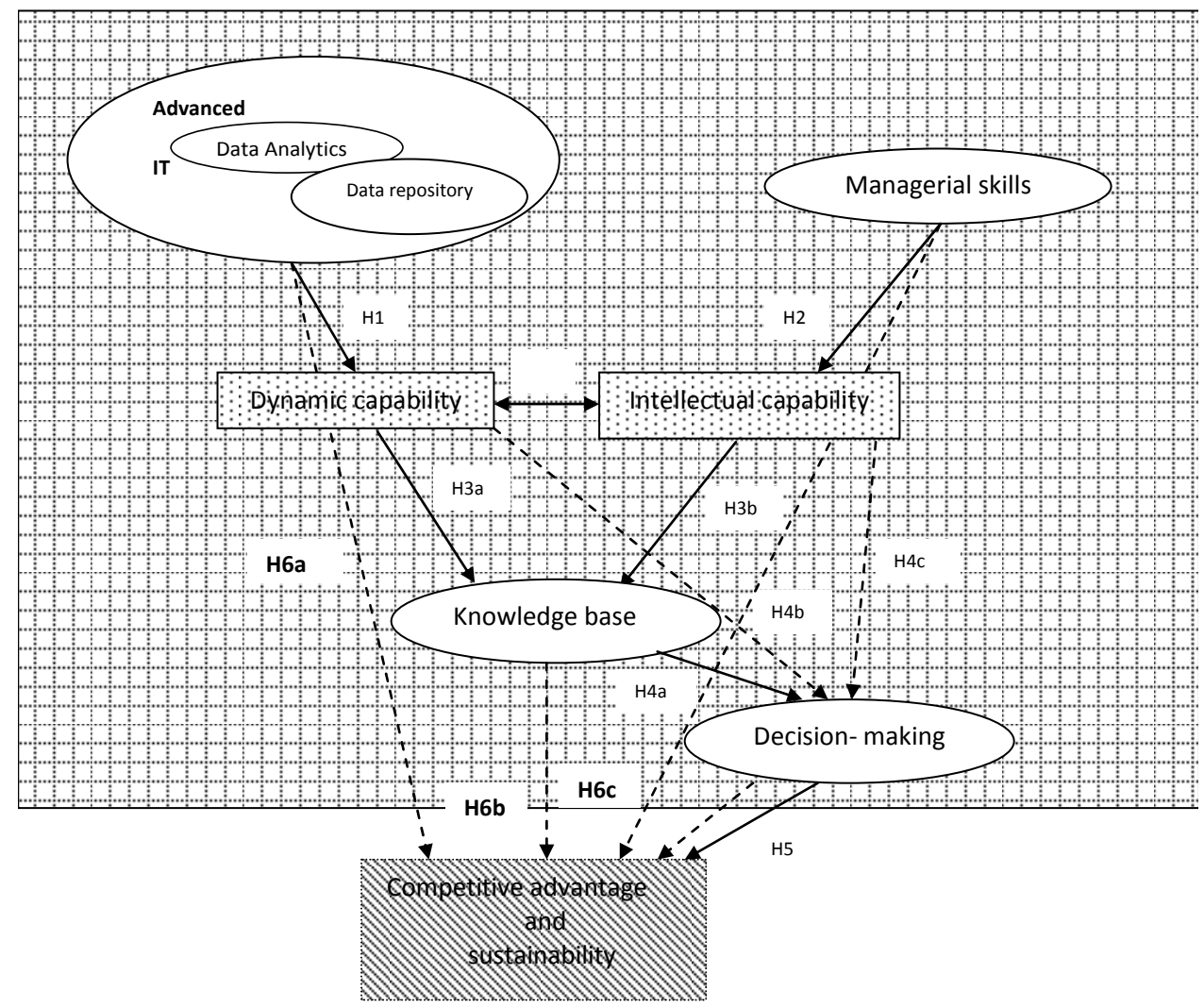

Thus, we can infer that besides data analytics, managerial skills help in business sustainability. The paper fills the gap in research by examining the relationship between sustainable business and various components of the environment that bring in sustainability. Based on all the above, it is hypothesised that:

H1 Availability of advanced IT features, i.e., data repository and data analytics tools are significant to dynamic capability of the organisation.

H2 Ability of managers to understand business context has significant effect on creating intellectual capability of the organisation.

H3 Use of data analytics and managerial skills have significant effect on creating knowledge base.

H4 Use of data analytics and managerial skills have significant effect on decision making process.

H5 Data-driven decision-making has significant effect on business sustainability. 
H6 Use of data analytics, managerial skills, decision making and knowledge base have significant impact on competitive advantage.

\section{Research approach}

The hypothesised relationships were tested using strategic level managers and IT professional in different sectors and different sized enterprises for two reasons:

1 Strategic level managers and IT professional are directly involved in decision-making process using data analytics, thus should effectively reflect the technology oriented and management oriented dimensions of our research model.

2 Data analytics being extensively used, dependent on amount of data availability and use of analytical tools, in all sectors and all types of enterprises, i.e., large, medium, small, organisation of different sizes were included in the survey.

The scope of the research is restricted to the National capital region, Delhi. The data collected by administering the questionnaire. Throughout the questionnaire, seven-point-Likert-type scales were used extending from 'strongly-disagree' (1) to 'strongly-agree' (7). Since the research is grounded on organisational level constructs, higher level managers and IT professionals were established as key informants.

\subsection{Data collection procedure}

Being an exploratory research, a survey was administered to gather data to test our research model and hypotheses. A draft questionnaire was pretested by 21 academicians and strategic level managers to ensure relevance, clarity and meaningfulness of the questionnaire. 213 questionnaires administered to the target audience (profile of the respondents, industry type and size of the organisation is given in Tables 2, 3 and 4 respectively). The valid and usable questionnaires were 132 in total with a response rate of $61.9 \%$ response rate. They worked in organisations with different sizes, i.e., $16 \%$ from small enterprises with less than 50 employees; 36\% from medium sized with 50-500 employees; and $48 \%$ from large organisations with more than 500 employees. $83 \%$ of the respondents were from service sector (marketing, telecommunication, insurance, and health) and $17 \%$ (social media). In these organisations, data analytics use ranged from 'not much' to 'fairly often' to 'often' (only measure which is not on seven-point scale).

The present study used structured equation modelling-SEM (Anderson and Gerbing, 1998) to test the relations and validate the research model. This method is frequently used and preferred by researchers to test models with simultaneous linkages between investigated variables.

Table 2 Demographic profile of respondents $(n=213)$

\begin{tabular}{lc}
\hline Target audience & Participation in percentage (\%) \\
\hline Strategic managers & 46 \\
Data analysts & 21 \\
IT managers & 33 \\
\hline
\end{tabular}


Table 3 Distribution of respondents as per size of organisations $(n=213)$

\begin{tabular}{|c|c|}
\hline Size of organisations & Respondents in percentage (\%) \\
\hline Small & 16 \\
\hline Medium & 36 \\
\hline Large & 48 \\
\hline \multicolumn{2}{|c|}{ Distribution of respondents as per type of organisations $(n=213)$} \\
\hline Size of organisations & Respondents in percentage (\%) \\
\hline Marketing; telecommuncation; & 83 \\
\hline \multicolumn{2}{|l|}{ Insurance; and health } \\
\hline Social media & 17 \\
\hline
\end{tabular}

\section{Data analysis and results}

\subsection{Measurement model}

In the first step, confirmatory factor analyses (CFA) was directed to estimate the validity of the scale (content, convergent and discriminant validity) and assess the reliability Table 5 reports mean, standard deviation and correlation. Results reveal that the highest correlation coefficient exist (0.686) between data analytics and decision-making. Also there is strong correlation between decision making and managerial skills (0.476).

Table 5 Descriptive statistics and correlation (see online version for colours)

\begin{tabular}{lcccccccccc}
\hline \multirow{2}{*}{ Constructs } & Mean & \multirow{2}{*}{ S.D. } & AVE & \multicolumn{7}{c}{ Correlation between constructs } \\
\cline { 5 - 11 } & & & & $D A$ & $M S$ & $K B$ & $D A T$ & $D R$ & $D M$ & $C A$ \\
\hline DA & 4.48 & .523 & .902 & 1 & & & & & & \\
MS & 3.45 & 1.04 & .760 & $.414^{* *}$ & .1 & & & & & \\
KB & 3.56 & .830 & .745 & $.426^{* *}$ & $.363^{* *}$ & 1 & & & & \\
DAT & 4.42 & 1.61 & .568 & $.465^{* *}$ & $.042^{*}$ & $.402^{*}$ & 1 & & & \\
DR & 3.13 & 1.04 & .657 & $.412^{* *}$ & $.212^{* *}$ & $.356^{* *}$ & $.449^{*}$ & 1 & & \\
DM & 5.83 & 1.86 & .843 & $.686^{* *}$ & .476 & $.315^{*}$ & $.521^{* *}$ & $.228^{* *}$ & & 1 \\
CA & 4.82 & .766 & .846 & $.576^{* *}$ & .476 & $.345^{*}$ & $.231^{* *}$ & $.218^{* *}$ & $.418^{* *}$ & 1 \\
\hline
\end{tabular}

Notes: S.D - standard deviation, DA - data analytics, MS - managerial skills,

$\mathrm{KB}$ - knowledge base, DAT - data analytics tools, DR - data repository,

$\mathrm{DM}-$ decision making, $\mathrm{CA}-$ competitive advantage. ${ }^{* * *} p<0.001, * * p<0.05$.

\subsubsection{Reliability and validity}

To ensure significant statistical outcomes from the proposed research model, the statistical reliability of the scale was calculated, on the basis of factor loadings $(\geq 0.7)$, composite reliability index $(\mathrm{CR})(\geq 0.6)$ and Cronbach's coefficient $(\geq 0.6)$ (Hair et al., 1998). In the present model, each measure satisfies the suggested threshold, factor 
loadings of all items were higher than 0.7, Cronbach's coefficient all measures were above 0.753 , and composite reliability were above 0.735 .

Further, average variance extracted (AVE) was calculated to evaluate statistical validity of the scale. The squared correlation of the construct as well as any of the other construct in the study should be greater than each construct's AVE (Fornell and Larcker, 1981) as given in Table 5. This supports discriminant validity.

\subsubsection{Structural model}

Next, the significance of each hypothesised relationship of the research model was tested. In the first hypothesis (H1), analytical results established significant relationship of data repository and data analytics tools with dynamic capability of the organisation $(\beta=.252$, $\rho=0.02)$.

In second hypothesis (H2), i.e., analytical results established ability of managers to understand business context has significant effect on creating intellectual capability of the organisation $(\beta=.284, \rho=0.003)$. In H3 cluster $(\mathrm{H} 3 \mathrm{a}, \mathrm{H} 3 \mathrm{~b})$ analytical results found that data analytics $(\beta=.345, \rho=0.002)$ and managerial skills $(\beta=.205, \rho=0.002)$ have significant effect on creating knowledge base.

In cluster $(\mathrm{H} 4 \mathrm{a}, \mathrm{H} 4 \mathrm{~b}, \mathrm{H} 4 \mathrm{c})$, the results established significant effect of data analytics $(\beta=.305, \rho=0.001)$ and managerial skills $(\beta=.245, \rho=0.002)$ on decision making process. In hypothesis (H5), i.e., analytical results established significant effect of data-driven decision-making $(\beta=.245, \rho=0.002)$ on competitive advantage of the organisation. In H6 cluster (H6a, H6b, H6c, H6d) results found a significant effect of data analytics $(\beta=.215, \rho=0.001)$, managerial skills $(\beta=.167, \rho=0.002)$, knowledge base $(\beta=.138, \rho=0.002)$ and decision making $(\beta=.197, \rho=0.001)$ on competitive advantage.

\section{Conclusions}

Literature disclosed that only $25 \%$ of the organisations reported that the use of analytics has 'significantly' improved their organisation's outcomes (Deloitte, 2013). The empirical analysis of has revealed some key findings. The analytical results reveal that data analytics is an important component of dynamic capabilities of the organisations but going by literature no all the companies investing in data analytics experience competitive advantage. The findings further have revealed the necessity of managerial skills to understand business context before the use of data analytics. There is significant level of link between data/knowledge repository, data analytics tools and understanding of business context by strategic managers; and competitive advantage.

This study confirms the role of managerial skills to harness the benefit from data analytics capabilities of the organisations. In essence, our findings portray that simple use of data analytics in business is advertised more as a complete data-driven environment has to be established in the organisations, which includes data repository; data analytics tools; knowledge base; business context, etc. An appropriate calibration of organisational resources related to data analytics is significant in even analysing the need, role and benefit of data analytics in business sustainability. 


\section{Theoretical contributions of the study}

This study addresses the under-explored issues left by researchers in BA. First, the study funds to the emerging knowledge on role of data analytics in business sustainability. The study postulates explicit details on the role of specific data driven environment in decision making. Third, this study fulfils the methodological demand of the contribution of data analytics as dynamic and managerial skills as intellectual capabilities in sustaining the business. Overall, this study is a contribution towards application data analytics in different sectors.

\section{Managerial implications of the study}

The study puts forward intellectual capital (managerial skills to understand the business context) as a vital driver and clarifies its role in gaining competitive advantage. Thus, this study serves decision makers a base in promoting the use data analytics for strategic decision for business sustainability.

\section{Limitations and directions for further research}

The study gathered data at one point in time. A longitudinal study would have gained better insight of data analytics in business sustainability. Further, it may be more interesting to use more objective data sets to predict the impacts data analytics along with managerial skills. We also acknowledge that the future research must include samples drawn from multiple geographies and conducted over a longer period.

\section{Acknowledgements}

I acknowledge the support provided by all the organisations and the employees (strategic level managers and the technical experts) who participated in the research.

\section{References}

Akter, S., Wamba, S.F., Gunasekaran, A., Dubey, R. and Childe, S.J. (2016) 'How to improve firm performance using big data analytics capability and business strategy alignment?', International Journal of Production Economics, Vol. 182, pp.113-131.

Ambrosini, V. and Bowman, C. (2009) 'What are dynamic capabilities and are they a useful construct in strategic management?', International Journal of Management Reviews, Vol. 11, No. 1, pp.29-49.

Ambrosini, V., Bowman C. and Collier, N. (2009) 'Dynamic capabilities: an exploration of how firms renew their resource base', British Journal of Management, Vol. 20, No. 1, pp.9-24.

Anderson, J.C. and Gerbing, D.W. (1988) 'Structural equation modelling in practice: a review and recommend two-step approach', Psychological Bulletin, Vol. 103, No. 3, pp.411-423.

Arend, R.J. and Bromiley, P. (2009) 'Assessing the dynamic capabilities view: spare change, everyone?’, Strategic Organization, Vol. 7, No. 1, pp.75-90. 
Baesens, B., Bapna, R., Marsden, J.R., Vanthienen, J. and Zhao, J.L. (2016) 'Transformational issues of big data and analytics in networked business', MIS Quarterly, Vol. 40, No. 4, pp.807-818.

Brown, B., Chui, M. and Manyika, J. (2011) 'Are you ready for the era of 'big data', McKinsey Quarterly, Vol. 4, pp.24-35.

Brynjolfsson, E. and McAfee, A. (2012) Race Against the Machine: How the Digital Revolution is Accelerating Innovation, Driving Productivity, and Irreversibly Transforming Employment and the Economy, Brynjolfsson and McAfee, Upper Saddle River, NJ.

Chae, B.K., Yang, C., Olson, D. and Sheu, C. (2014) 'The impact of advanced analytics and data accuracy on operational performance: a contingent resource based theory (RBT) perspective', Decision Support Systems, Vol. 59, pp.119-126.

Chen, H., Chiang, R.H.L. and Storey, V.C. (2012) 'Business intelligence and analytics: from big data to big impact', MIS Quarterly, Vol. 36, No. 4, pp.1165-1188.

Collins, R. (2010) A Graphical Method for Exploring the Business Environment [online] http://users.ox.ac.uk/ kell0956/docs/PESTLEWeb.pdf (accessed 17 December 2017).

Davenport, T.H. (2006) 'Competing on analytics', Harvard Business Review, Vol. 84, No. 1, pp. $1-10$

Deloitte (2013) The Analytics Advantage we're Just Getting Started from [online] https:/www2.deloitte.com/content/dam/Deloitte/global/Documents/Deloitte-Analytics/dttlanalytics-analytics-advantage-report-061913.pdf (accessed 17 December 2017).

Fornell, C. and Larcker, D.F. (1981) 'Evaluating structural equation models with unobservable variables and measurement error', Journal of Marketing Research, Vol. 18, No. 1, pp.39-50.

Garg, A. and Singla, N. (2017) 'Environment sustainability awareness model for IT SMEs', Interdisciplinary Environmental Review, International Journal, Vol. 18, No. 1, pp.1-5.

Grover, V. and Kohli, R. (2012) 'Co creating IT value: new capabilities and metrics for multifirm environments', MIS Quarterly, Vol. 36, No. 1, pp.225-232.

Helfat, C.E. and Peteraf, M.A. (2009) 'Understanding dynamic capabilities: progress along a developmental path', Strategic Organization, Vol. 7, No. 1, pp.91-102.

Helfat, C.E., Finkelstein, S., Mitchell, W., Peteraf, M.A., Singh, H., Teece, D.J. and Winter, S.G. (2007) Dynamic Capabilities: Understanding Strategic Change in Organizations, Blackwell, Malden, MA, USA.

Hodgkinson, G.P. and Healey, M.P. (2011) 'Psychological foundations of dynamic capabilities: reflexion and reflection in strategic management', Strategic Management Journal, Vol. 32, No. 13, pp.1500-1516.

Joshi, K.D., Chi, L., Datta, A. and Han, S. (2010) 'Changing the competitive landscape: continuous innovation through IT-enabled knowledge capabilities', Information Systems Research, Vol. 21, No. 3, pp.472-495.

Li, D.Y. and Liu, J. (2014) 'Dynamic capabilities, environmental dynamism, and competitive advantage: evidence from China', Journal of Business Research, Vol. 67, No. 1, pp.2793-2799.

Marques, F., Sérgio Miranda Mendonça, P. and Chiappetta Jabbour, C.J. (2010) 'Social dimension of sustainability in retail: case studies of small and medium Brazilian supermarkets', Soc. Respon. J., Vol. 6, No. 2, pp.237-251.

Mintzberg, H. (1973) The Nature of Managerial Work, Harper and Row, New York.

Park-Poaps, H. and Rees, K. (2010) 'Stakeholder forces of socially responsible supply chain management orientation', J. Bus. Ethics, Vol. 92, No. 2, pp.305-322.

Pavlou, P.A. and El Sawy, O.A. (2010) 'The 'third hand': IT-enabled competitive advantage in turbulence through improvisational capabilities', Information Systems Research, Vol. 21, No. 3, pp.443-471.

Peteraf, M.A. (1993) 'The cornerstones of competitive advantage', Strategic Management Journal, Vol. 14, No. 3, pp.179-191. 
Ramakrishnan, T., Khuntia, J., Saldanha, T. and Kathuria, A. (2015) 'Business intelligence capabilities and organizational performance', in Proceedings of the Fourth Annual Business Analytics Congress, Fort Worth, Texas.

Roberts, N. and Grover, V. (2012) 'Leveraging information technology infrastructure to facilitate a firm's customer agility and competitive activity: an empirical investigation', Journal of Management Information Systems, Vol. 28, No. 4, pp.231-270.

Sallam, R.L., Tapadinhas, J., Parenteau, J., Yuen, D. and Hostman, B. (2014) Magic Quadrant for Business Intelligence and Analytics Platforms, Stamford, CT.

Sharma, R., Reynolds, P., Scheepers, R., Seddon, P.B. and Shanks, G. (2010) 'Business analytics and competitive advantage: a review and research agenda', in Respicio, A., Adam, F., Phillips, G., Teixeira, C. and Telhada, J. (Eds.): Bridging the Socio-Technical Gap in Decision Support Systems: Challenges for the Next Decade, pp.187-198, IOS Press, Amsterdam, Netherlands.

Song, M., Cen, L., Zheng, Z., Fisher, R., Liang, X., Wang, Y. and Huisingh, D. (2017) 'How would big data support societal development and environmental sustainability? Insights and practices', J. Clean. Prod., Vol. 142, pp.489-500.

Teece, D.J., Pisano, G. and Shuen, A. (1997) Dynamic Capabilities and Strategic Management [online] http://books.google.ca/books?hl=en\&lr=\&id=hDzMIC8mij4C\&oi=fnd\&pg= PA234\&dq (accessed 20 March 2017).

Teece, D.J. (2007) Explicating dynamic capabilities: the nature and microfoundations of (sustainable) enterprise performance', Strategic Management Journal, Vol. 28, No. 13, pp.1319-1350.

Teece, D.J. (2014) 'A dynamic capabilities-based entrepreneurial theory of the multinational enterprise', Journal of International Business Studies, Nature Publishing Group, Vol. 45, No. 1, pp.8-37.

Wamba, S.F., Gunasekaran, A., Akter, S., Ren, S.J., Dubey, R. and Childe, S.J. (2017) 'Big data analytics and firm performance: effects of dynamic capabilities', Journal of Business Research, Vol. 70, No. 1, pp.356-365, Elsevier Inc.

Wixom, B.H. and Watson, H.J. (2010) 'The BI-based organization', International Journal of Business Intelligence Research, Vol. 1, No. 1, pp.13-28.

Zott, C. (2003) 'Dynamic capabilities and the emergence of intraindustry differential firm performance: insights from a simulation study,' Strategic Management Journal, Vol. 24, No. 2, pp.97-125.

Seddon, P.B., Constantinidis, D., Tamm, T. and Dod, H. (2017) 'How does business analytics contribute to business value?', Information Systems Journal, Vol. 27, No. 3, pp.237-269.

Helfat, C.E. and Peteraf, M.A. (2014) 'Managerial cognitive capabilities and the microfoundations of dynamic capabilities', Strategic Management Journal, Vol. 36, No. 6, pp.831-850.

Hair, J.F. Jr., Anderson, R.E., Tatham, R.L. and Black, W.C. (1998) Multivariate Data Analysis, 5th ed., Prentice Hall, Upper Saddle River, NJ. 